\title{
A DOUBLE-BLIND STUDY TO DETERMINE THE MAXIMUM TOLERATED DOSE OF ETHIONAMIDE, WHEN ADMINISTERED TWICE-WEEKLY TO PATIENTS WITH PULMONARY TUBERCULOSIS
}

\author{
S. DEVADATTA, N.K. MENON, O. NAZARETH, S. RADHAKRISHNA, \\ C.V. RAMAKRISHAN, P.R. SOMASUNDARAM, S.P. USHA AND S. VELD* \\ (From the Tuberculosis Chemotherapy Centre, Madras)
}

\section{Introduction}

ATI earlier report from this Centre (Tuberculosis Chemotherapy Centre, Madras, 1964) showed that a fully supervised twice-weekly regimen of streptomycin plus high-dosage isoniazid was highly effective in the treatment of patients with newly-diagnosed bacteriologically confirmed pulmonary tuberculosis. However, this regimen involves intramuscular injections of streptomycin and may not always be easy to organize, especially in rural areas and in developing countries with limited resources. For this reason, it was decided to investigate the possibility of replacing streptomycin in the twice-weekly regimen by two oral drugs, namely ethionamide and PAS. Ethionamide was chosen since, apart from isoniazid and streptomycin, it was the most potent drug available at the time, and PAS was included with a view to enhance the efficacy of the regimen. Finally, it was decided that the patients should be given an intensive phase of daily treatment with streptomycin, PAS and isoniazid for two weeks.

Experiments in the guinea-pig had shown that the size of the individual dose of a drug needed to be increased as the interval between successive doses was increased (Dickinson \& Mitchison, 1966). As PAS is bulky and the dosage of isoniazid in the twice-weekly regimen was already high, namely $15 \mathrm{mg} . / \mathrm{kg}$. bodyweight, it was decided to explore the possibility of increasing the dosage of ethionamide to a level higher than that usually employed (0.51.0 g.) in daily regimens. An investigation was therefore undertaken to determine the maximum tolerated dose of ethionamide. when administered twice-weekly together with isoniazid plus PAS. Since the assessment of ethionamide intolerance is largely subjective, the study was conducted 'double-blind' with respect to the dosage of ethionamide.

\section{Plan and conduct of the study}

The patients came from the poorest sections of the population of Madras City, were aged 12 years or more and had newly-diagnosed

* Deceased. bacteriologically confirmed

pulmonary tuberculosis.

\section{Treatment}

In the first two weeks, the patients received daily chemotherapy with streptomycin I g., sodium PAS $6 \mathrm{~g}$. (in four cachets) and isoniazid $400 \mathrm{mg}$. as a single tablet incorporating pyridoxine $6 \mathrm{mg}$. Subsequently,they received a twice-weekly regimen of sodium PAS $6 \mathrm{~g}$., isoniazid $15 \mathrm{mg} . / \mathrm{kg}$. body-weight* (incorporating pyridoxine $6 \mathrm{mg}$.) and ethionamide in the dosage described below, all the drugs being administered at the same time in a single dose under the direct supervision of a nurse at the Centre.

\section{Plan of administration of ethionamide}

The prescription of ethionamide was made, in accordance with the plan below, by one of two physicians ('prescribing' physicians), neither of whom interviewed the patients after the commencement of treatment.

Ethionamide was administered to the patients in cachets, each cachet containing either one or two uncrushed tablets of ethionamide $0.25 \mathrm{~g}$.; these cachets were identical in appearance to the cachets containing PAS.

\section{Short-term study}

To begin with, ethionamide was administered in a dose of $0.5 \mathrm{~g}$. on four occasions, together with isoniazid and PAS, at intervals of three and four days alternately.

(A) If clear-cut intolerance (that is, intolerance warranting a modification of treatment) did not occur, the dose was increased by $0.25 \mathrm{~g}$.; for the next four occasions. This procedure after every fourth dose until a dose of $1.5 \mathrm{~g}$. had been tolerated on four consecutive occasions, unless clear-cut intolerance was reported.

(B) If clear-cut intolerance to any dose was observed, ethionamide was withdrawn, and

* that is, $400 \mathrm{mg}$., $600 \mathrm{mg}$. and $750 \mathrm{mg}$. for patients weighing less than $30.0 \mathrm{~kg}$., $30.0-44.9 \mathrm{~kg}$. and $45.0 \mathrm{~kg}$. or more, respectively.

Ind. J. Tub., Vol. XVII, No.4 
instead, an equal number of dummy cachets** was prescribed for two weeks, or longer if the toxic manifestations persisted. At the end of this period, ethionamide was reintroduced in the same dose and tentatively prescribed for four occasions.

(1) If clear-cut intolerance did not reemerge, the dose of ethionamide was increased by $0.25 \mathrm{~g}$. for the next four occasions, the subsequent management being as stated in $(A)$ and $(B)$.

(2) If dear-cut intolerance did re-emerge, it was considered that the maximum tolerated dose (defined below) had been established. Ethionamide was withdrawn for two weeks (or longer if the toxic manifestations persisted), and an equal number of dummy cachets prescribed. At the end of this period, a longer-term study was commenced.

\section{Definition of maximum tolerated dose of ethionamide}

The maximum tolerated dose of ethionamide for a patient was defined as the highest dose of ethionamide (not exceeding $1.5 \mathrm{~g}$.) tolerated twice-weekly for two weeks.

\section{Longer-term study}

Once the maximum tolerated dose of ethionamide was determined, the aim was to prescribe this dose for a period of eight weeks, in order to obtain information on longer-term tolerance. If clear-cut intolerance emerged at any time during the eight weeks, ethionamide was withdrawn and the patient prescribed dummy cachets for two weeks, or longer if the toxic manifestations persisted. At the end of this period, ethionamide was introduced in a dose which, was lower by $0.25 \mathrm{~g}$, and prescribed for a period of eight weeks. This procedure was repeated, if necessary.

\section{Assessment of intolerance to ethionamide}

The assessment of intolerance lo ethionamide was undertaken by three physicians ('assessing' physicians), who were unaware of

** The dummy cachets, each containing a tablet of calcium gluconate $0,5 \mathrm{~g}$., were identical in appearance to those containing ethionamide. They were employed in order to conceal, both from the patient and the 'assessing' physicians that ethionamide was being withdrawn during this period. However, to reassure the patient that some action had been taken following the complaints of side-effects, one undisguised placebo tablet (calcium gluconate 0.5 g.) was also administered with each dose. the plan of administration of ethionamide. In consequence, although they knew that the patients were attending the Centre twice a week to receive an ethionamide-containing regimen, they had no knowledge of the dose of ethionamide received by any patient at any point in time during the study.

At the start of treatment, the patients were allotted in equal numbers to the three assessing physicians. On all subsequent occasions, that is, (a) at monthly examinations, (b) after spontaneous complaints, and (c) after default from attendance, each patient was seen by his assessing physician. The patients were never questioned to elicit symptoms of intolerance to ethionamide. However, whenever a spontaneous complaint was made, the assessing physician interrogated the patient carefully and assessed the severity of the symptoms. If the symptoms were mild, he reassured the patient and persuaded him to continue the chemotherapy. If however, the symptoms were severe or persistent (clear-cut intolerance), he recommended a modification of treatment. The actual modification was made, in accordance with the design of the study, by one of the two prescribing physicians. Autiemetic drugs, antihismines and tranquilizers, which might have ameliorated the symptoms, were not prescribed.

\section{Results}

In all, 30 patients were admitted to the study. Of these, three stopped attending the Centre, because of domestic problems, before their maximum tolerated dose could be determined. Two were receiving $1.0 \mathrm{~g}$, of ethionamide and the third $0,75 \mathrm{~g}$. at the time. There remain 27 patients (18 males, nine females) in the analysis. Of these, 15 were aged less than 35 years, six were aged $35-44$ years and six were aged 45 years or more. The weight was less than $30.0 \mathrm{~kg}$. in two, $30.0-44.9 \mathrm{~kg}$. in 19 , and $45.0 \mathrm{~kg}$. or more in the remaining six.

\section{Maximum tolerated dose of ethionamide}

Table 1 presents the distribution of patients according to the maximum dose tolerated on four consecutive occasions. Of the 27 patients, 10 (37 per cent) tolerated the highest planned dose of $1.5 \mathrm{~g}$., while three (11 per cent) tolerated $1.25 \mathrm{~g}$. On the other hand, four (15 per cent) tolerated only $0.5 \mathrm{~g}$. and five (19 per cent) tolerated $0.75 \mathrm{~g}$. but not more. When expressed as mg./kg. body-weight, the maximum tolerated dose was $40 \mathrm{mg} . / \mathrm{kg}$. or more for four (15 per cent) patients and 30-39 $\mathrm{mg} . / \mathrm{kg}$. for seven (26 per cent) ; however, it was $19 \mathrm{nig} . / \mathrm{kg}$. or less for seven (26 per cent) patients. 
TABLE I

Maximum tolerated dose of ethionamide

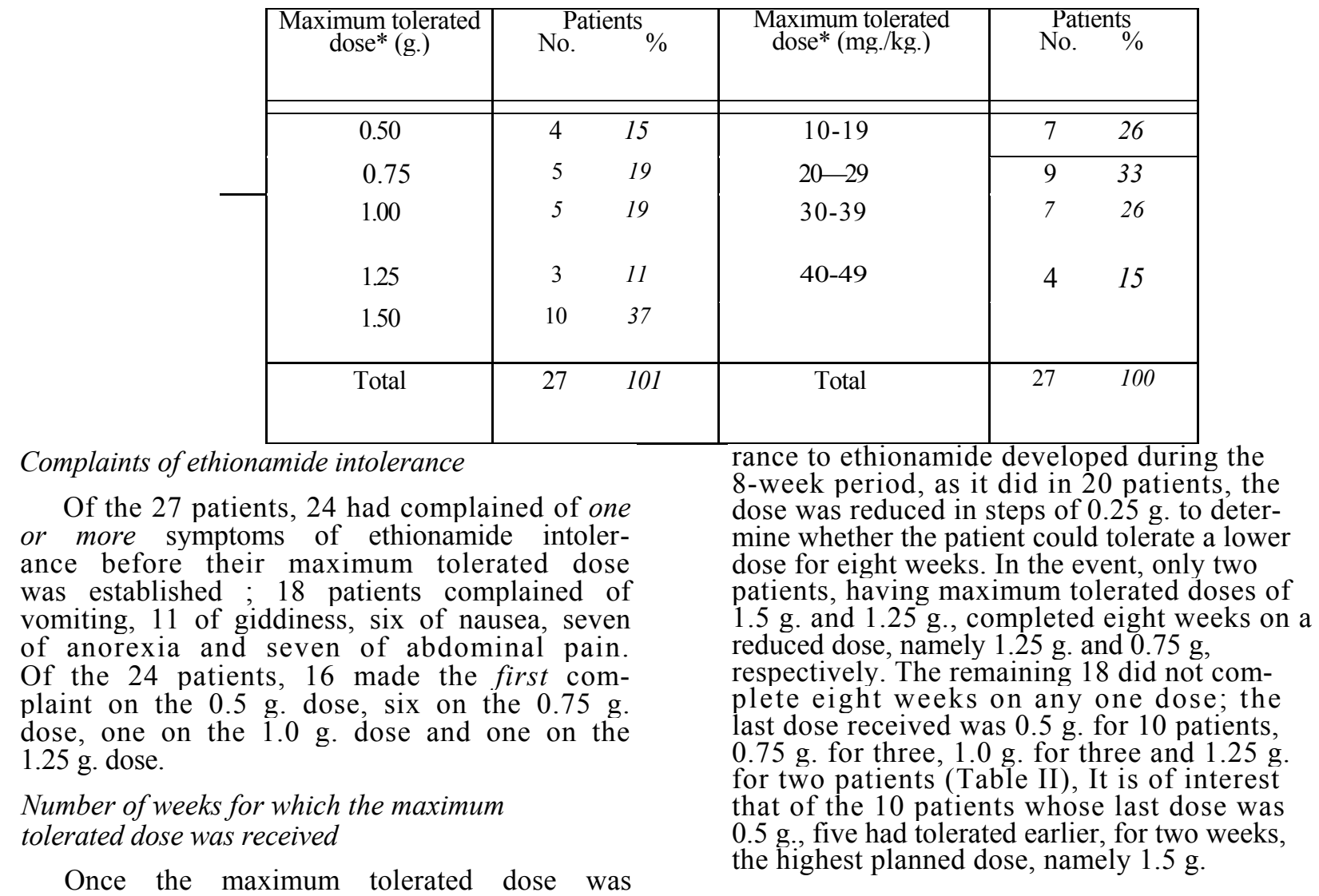
determined, the aim was, as already stated, to prescribe it for a further period of eight weeks. In the event, this was not attempted for four patients (with maximum tolerated doses of $0.5,0.5,0.75$ and 1.0 g.), mainly because of non-cooperation induced by the occurence of ethionamide intolerance in the course of determining the maximum tolerated dose. Another patient, whose maximum tolerated dose was 1.0 g., developed peripheral neuropathy attributed to isoniazid and was withdrawn from the study. Of the remaining 22 patients, only two, both with a maximum tolerated dose of $1.5 \mathrm{~g}$., completed the 8-week period on this dose. Indeed, of the 20 patients who did not complete the 8-week period, 17 developed clear-cut intolerance within two weeks, and remaining three in the third, the fifth and the seventh week.

Tolerance, over an 8-week period, of doses lower than the maximum tolerated dose

It will be recalled that if clear-cut intole-

When expressed as mg./kg. body-weight, the last dose received was less than $20 \mathrm{mg} . / \mathrm{kg}$. in 14 (78 per cent) of the 18 patients. In none of the patients was it $30 \mathrm{mg} . / \mathrm{kg}$. or more, although 6 (33 per cent) of them had earlier tolerated $30-45 \mathrm{mg} . / \mathrm{kg}$. for two weeks.

\section{Omission of PAS}

Since PAS, like ethionamide, is capable of producing gastro-intestinal side-effects, it was thought that its omission might result in higher values for the maximum tolerated dose of ethionamide. Consequently, a further group of 30 patients (18 males, 12 females) was investigated, the plan of the study being the same except that no PAS was prescribed.

Of the 30 patients, one could not tolerate even $0.5 \mathrm{~g}$. of ethionamide ; the maximum tolerared dose was $0.5 \mathrm{~g}$. for seven patients, $0.75 \mathrm{~g}$, for two, $1.0 \mathrm{~g}$. for four, $1.25 \mathrm{~g}$. for

Ind. J. Tub., Vol, XVII, No.4 
TAULE II

Last dose of ethionamide received by patients who did not complete eight weeks on any one dose

\begin{tabular}{|c|c|cccccc|}
\hline \multirow{2}{*}{$\begin{array}{l}\text { Last dose of } \\
\text { ethionamide } \\
\text { received (g.) }\end{array}$} & \multirow{2}{*}{$\begin{array}{l}\text { Total } \\
\text { patients }\end{array}$} & \multicolumn{5}{|c|}{ Maximum } & tolerated dose* (g.) \\
\cline { 3 - 6 } & & 0.50 & 0.75 & 1.00 & 1.25 & 1 & 50 \\
\hline 0.50 & 10 & 2 & 1 & 2 & 0 & 5 \\
0.75 & 3 & - & 3 & 0 & 0 & 0 \\
1.00 & 3 & - & - & 1 & 1 & 1 \\
1.25 & 2 & - & - & - & 1 & 1 \\
\hline & 18 & 2 & 4 & 3 & 2 & 7 \\
\hline
\end{tabular}

seven and $1.5 \mathrm{~g}$, for nine patients. Thus, one-third of the patients (10 of 30$)$ could not tote-rate even $1.0 \mathrm{~g}$. (it will be recalled that the corresponding proportion in patients who received PAS in addition to ethionamide and isoniazid was indentical, namely nine of 27). When these findings became known, the study of longer-term tolerance was terminated.

\section{Maximum tolerated dose of ethionamide related to sex, age and weight}

Since females have been reported to have a higher incidence of ethionamide side-effects than males (Verbist and others, 1967 ; Fox and others, 1969), the data were examined for the presence of an association between sex and the maximum tolerated dose in the 57 patients reported in this paper. On average, the maximum tolerated dose was $1.03 \mathrm{~g}$. for 36 males compared with $1.14 \mathrm{~g}$. for 21 females, a non-significant difference $(\mathrm{P}=0.3)$.

There was also no evidence that the maximum tolerated dose was influenced by either the age or the weight of the patient.

\section{Discussion}

The 'double-blind' investigation reported here was undertaken to determine the maximum dose of ethionamide that could be administered twice weekly to patients with newly-diagnosed bacteriologically confirmed pulmonary tuberculosis. The results are disappointing in that one-third of the patients could not tolerate even $1.0 \mathrm{~g}$. of ethionamide twice-weekly for two weeks, when the drug was administered with isoniazid plus PAS or, indeed, with isoniazid alone. Moreover, of 22 patients who were prescribed their maximum tolerated dose (that is, the maximum dose tolerated on four consecutive occasions) for a period of eight weeks, 20 developed clear-cut intolerance during this period, 17 of them within two weeks. Indeed, nearly all had had symptoms of intolerance before they attained their maximum tolerated dose. These findings are discouraging for the long-term use of even a moderately high dosage of ethionamide on a twice-weekly basis in Madras patients.

Fox and others (1969) studied, also in a 'double-blind' investigation, acute intolerance to individual doses of ethionamide and prothionamide in East African patients who were under treatment with a daily regimen of isoniazid plus streptomycin. They concluded that in these patients, it would not be possible, as a routine, to increase the dosage of either ethionamide or prothionamide in intermittent regimens above the conventional dosages used in daily regimens.

It has been reported by Prignot, Everaents and Tyberghein (1962) and Gyselen and others (1963) that vitamin B-complex preparations substantially reduce the frequency and severity of the side-effects of ethionamide. Later studies, however, have shown that this is not the case (Verbist and others, 1967 ; Fox and others, 1969).

The design and conduct of this study merit special mention. The study was conducted 'double-blind' with respect to ethionamide 


\section{S. DEVADATTA AND OTHERS}

dosage because the assessment of ethionamide intolerance is largely subjective. Further, the plan according to which the ethionamide was administered was withheld from the physicians who assessed intolerance to the drug. In consequence, although these physicians knew that the patients were attending the Centre twice a week to receive an ethionamide-containing regimen, they were completely unaware of the dose of ethionamide received by any patient at any point in time during the study. Indeed, they were not even aware that the aim was to increase the dose gradually to $1.5 \mathrm{~g}$. for each patient, that tolerance to each dose was to be assessed on four consecutive occasions or that the ethionamide was temporarily withdrawn whenever clear-cut intolerance developed. Next, by prescribing for eight weeks the maximum dose which had been tolerated on four consecutive occasions, valuable information has been obtained on longer-term tolerance to the drug. The finding that the maximum dose could seldom be tolerated for eight weeks emphasizes the need to have adequately long periods of observation in studies undertaken to assess tolerance to ethionamide.

We are grateful to the clinic nurses who played an important role in the conduct of this 'double-blind' study.

\section{Summary}

A 'double-blind' study was undertaken to determine the maximum dose of ethionamide that could be tolerated for two weeks, when administered twice-weekly together with isoniazid plus PAS. Of 27 patients, 10 (37 per cent) tolerated the highest planned dose of $1.5 \mathrm{~g} . . ;$. . on the other hand, nine (33 per cent) could not tolerate even $1.0 \mathrm{~g}$.

Of 22 patients who were prescribed their maximum tolerated dose for a further period of eight weeks, only two completed the 8-week period on this dose; two more completed an 8-week period on a reduced dose.

The omission of PAS, in another group of 30 patients, did not result in better tolerance of ethionamide, the number who failed to tolerate $1.0 \mathrm{~g}$. for two weeks being 10 (33 per cent).

These findings are discouraging for the use of even a moderately high dosage of ethionamide on a twice-weekly basis in Madras patients.

\section{REFERENCES}

Dickinson, J.M., and Mitchison, D.A. (1966). Shortterm intermittent chemotherapy of experimental tuberculosis in the guinea-pig. Tubercle, Load., 41. 381.

Fox, W., Robinson, D.K., Tall, R., Mitchison, D.A., Kent, P.W., and Macfadyea, D.M. (1969). A study of acute intolerance to ethionamide, including a comparison with prothionamide. and of the influence of a vitamin B-complex additive in prophylaxis. Tubercle, Lond., 50, 125.

Gyselen, A., Prigaot, J., Cosemans, J., and Verbist, L. (1963). Experience sanatoriale des tuberculostatiques de relais. Lille Medical, 8, 1151,

Prignot, J., Everaerts, J., and Tyberghein, J. (1962). Manifestations d'intoierance et de toxicite an cours des traitements tuberculostatiques. Acta Tuberc, Pneumol. Belgica, 53, 276.

Tuberculosis Chemotherapy Centre, Madras (1964). A concurrent comparison of intermittent (twiceweekly) isoniazid plus streptomycin and daily isoniazid plus PAS in the domiciliary treatment of pulmonary tuberculosis. Bull. Wld Hlth Org., 31, 247.

Verbist, L., Prignot, J., Cosemans, J., and Gyselen, A. (1967). Tolerance to ethionamide and PAS in original treatment of tuberculosis patients. Scand, J, resp. Dis., 47, 225.

Ind. J. Tub., Vol. XVII, No.4 